\title{
LA RED DEL CORSARIO FRANCÉS JUAN CHEVALLIER Y SUS PRESAS ANGLOAMERICANAS EN EL CARIBE DURANTE LAS GUERRAS NAVALES (1796-1808)
}

\author{
THE NETWORK OF THE FRENCH PRIVATEER JUAN \\ CHEVALLIER AND HIS ANGLO-AMERICAN PREYS \\ IN THE CARIBEAN SEA DURING THE NAVAL WARS
} (1796-1808)

\author{
Julio César Rodríguez Treviño \\ Universidad Veracruzana, Xalapa, México \\ orfeoeuridice@hotmail.com
}

Resumen. Con el apoyo de las metodologías cualitativas y los programas computacionales del Análisis de Redes Sociales, desde la perspectiva de la histórica económica, las metas del presente artículo son dos. El primero es analizar los nexos de apoyo y antagónicos en el Caribe de un corsario francés, con patente de corso española, quien al apresar dos buques neutrales, rescató notas de carga auténticas y falsas, situación que nos permite estudiar un medio de protección mercantil utilizado por los comerciantes durante los viajes ultramarinos: los dobles registros simulados. El segundo objetivo es investigar los conflictos y pactos militares y comerciales de fines del siglo XVIII entre España, su virreinato septentrional, Francia, Inglaterra y el emergente Estados Unidos de Norteamérica, a través del juicio de comiso librado por el galo.

Palabras clave: corsario; red; comercio neutral; registro simulado.

Abstract. With the support of qualitative methodologies and computer programs of the Analysis Social Networks, from the perspective of economic history, the aims of this article are twofold. Analyze the links supporting and antagonistic in the Caribbean of a French privateer, with Spanish letter of marque which two neutral vessels to capture notes and genuine false charge, allows us to study a means of protection used by commercial traders during the overseas travel: simulated double registration. The second objective is through the forfeiture judgment delivered by the French, investigate the conflicts and military and commercial agreements of ends of the 18th century between Spain, his North viceroyalty, France, England and the emergent United States of North America.

Key words: privateer; network; neutral trade; simulated record.

Fecha de recepción: 9 de enero de 2014. Fecha de aceptación: 11 de junio de 2014.

Am. Lat. Hist. Econ., año 22, núm. 1, enero-abril, 2015, pp. 115-149 


\section{INTRODUCCIÓN*}

mediados de 1796, España y la Francia revolucionaria se aliaron
contra su enemigo común: Inglaterra; esa unión fue el inicio del
capítulo conocido como "las guerras navales" (1796-1808). Para la Real Armada de su majestad católica, el conflicto representó derrotas y bloqueos portuarios que afectaron negativamente la Carrera de Indias; ante ello, por grave necesidad, el gobierno español utilizó diversas concesiones para reactivar y dar seguridad a su comercio. Desde un enfoque económico-social, en este artículo se estudian tres de esas autorizaciones: la primera, las aperturas del comercio marítimo español a buques mercantes neutrales; la segunda, los permisos de carga conocidos como dobles registros de simulación otorgados por las autoridades españolas a los capitanes de barcos imparciales, y la tercera, las licencias de corso ${ }^{1}$ dadas a los aliados franceses en el Caribe hispano. Por medio de estas tres permisiones se da respuesta a la interrogante de cómo surgieron tales medidas y cuáles fueron las consecuencias del conflicto en el sistema de intercambio ultramarino. También, por medio de un estudio de caso, y con el apoyo metodológico del análisis de redes sociales, se busca dilucidar cuáles fueron las tensiones y apoyos entre los involucrados en la política naval-mercantil española de ese periodo.

Historiográficamente se han realizado múltiples trabajos sobre las tres autorizaciones. Entre los más relevantes, en materia de comercio neutral en la América española y los conflictos navales en los que se implicó España, se encuentran los de Carlos Marichal (2000) y Matilde Souto (2001), quienes indagan sobre las primera y segunda guerras navales y las importaciones y exportaciones legales e ilícitas realizadas en el puerto de Veracruz por barcos neutrales, por medio de las transacciones mercantiles de las casas comerciales estadunidenses y londinenses. Otro estudio es el de Guadalupe Jiménez (2000), en el que realizó un balance mercantil del comercio clandestino en los puertos del Caribe novohispano ejercido por neutrales. Humberto Tandrón (1976) estudió el tipo de barcos y las mercaderías que arribaron o zarparon de Veracruz y Campeche, y las consecuencias negativas del uso y paulatino aumento de neutrales en el mercado externo

* Este artículo fue realizado gracias al apoyo de la estancia posdoctoral en la Universidad Autónoma Metropolitana-Iztapalapa, y del Proyecto de Investigación Básica SEP-CONACYT 179035 del Instituto de Investigaciones Dr. José María Luis Mora.

${ }^{1}$ Las licencias o patentes de corso eran documentos solicitados por particulares y expedidos por las autoridades de gobierno; con ellas se facultaba a su poseedor, previo pago de una fianza, a salir a la mar con un buque y tripulación armada en nombre de la nación que se la concedió, a fin de vigilar las aguas y rutas comerciales de buques enemigos. A su vez, la patente daba a los particulares la legitimidad a sus acciones bélicas, con su posesión y en caso de ser aprendido por el enemigo era tratado como prisionero de guerra y no como pirata. 
novohispano. En el contexto del doble registro de simulación, trabajos como los de Cristina Mazzeo (2003), Carlos Marichal (2000) y John Fisher (1990) hacen mención del uso del doble registro bajo el nombre de licencia; destacan su uso como una forma para que navíos con pabellón neutral eviten el decomiso de mercancía española, estadunidense o británica por posibles enemigos, y subrayan la delgada línea entre este sistema y el contrabando. Sin embargo, el término doble registro de simulación no es usado, y no profundizan en tan inédito tema.

Respecto al corso, la obra clásica de José Luis de Azcárraga (1950) describe la historia del corso europeo en el medievo y el Caribe colonial hasta 1775. Un trabajo similar se encuentra en el apartado del libro de Manuel Lucena (1992), que describe la aparición y desarrollo del uso del corso en la América española; la investigación de Victoria Stapells (1992) abarca la vida de los corsarios en Santo Domingo desde 1718 hasta la década de 1770, así como las indagaciones de Óscar Cruz (1997 y 2013) quien desde el enfoque de la jurisprudencia abarca toda la historia del corso en la época colonial.

El análisis de redes sociales (ARS) es una herramienta metodológica que no sólo es utilizada por la sociología o la antropología, pues hoy en día la historia ha tomado líneas de investigación basadas en el estudio de los vínculos sociales, sobre todo a partir de la última década del siglo Xx, cuando los historiadores empezaron a abandonar el paradigma estructuralista que estableció las estructuras como condicionantes de las prácticas sociales; en su lugar se comenzó a revalorizar a los individuos como actores sociales dinámicos y forjadores de sucesos históricos. Ello gracias a la aplicación de la interdisciplinariedad de la historia, que renovó un diálogo con la antropología, la economía, la sociología y antiguos tópicos que son retomados como las nociones de red social y cultura, dándole así un nuevo giro a la imagen de los actores insertos pasivamente en los procesos históricos.

Esta revitalización se puede apreciar en un creciente grupo de historiadores que analizan los vínculos sociales de los actores, entre ellos Zacarías Moutoukias (1989, 1997, 1998), Miguel Rosal (1989), Michel Bertrand, (1999a, 1999b, 1999c), Matilde Souto (2001), Katherine Faust (2002), Linton Freeman (2002), Douglas R. White, Michael Schnegg, Lilyan A. Brudner y Hugo G. Nutini (2002), Narda Alcántara y Silvia Casasola (2002), Bernd Hausberger (2003), Clara Elena Suárez (2004), Macarena Perusset (2007), Antonio Ibarra y Guillermina del Valle (2007), Ernest Sánchez (2007), entre otros más.

Así, con la pluralidad de enfoques que hoy en día se reflejan en investigaciones aplicadas en la economía, la política, la religión, la sociedad, entre otras, el historiador ha retomado instrumentos analíticos como el uso 
de la teoría de redes sociales para el estudio de asuntos variados, ello para formular nuevos problemas sobre antiguas incógnitas (Bertrand, 1999b, pp. 35-51). Por ende, el historiador puede utilizar la red social como una forma visual de aproximarse e identificar las estructuras sociales que emergen de las diversas formas de relación existente en una determinada fase del tiempo y del espacio (Ibarra y Valle, 2007, pp. 717-723).

A fin de contribuir al campo historiográfico y profundizar en los planteamientos anteriormente descritos, hemos implementado la metodología del análisis de redes sociales, herramienta basada en un conjunto de instrumentos cualitativos aplicados a los actores o nodos (individuos, instituciones, corporaciones, medios de transporte, puntos geográficos) con las organizaciones sociales que resultan de las relaciones entre los integrantes de la red social. ${ }^{2}$ Este sistema de investigación consiste en una serie de preguntas estratificadas aplicadas a las fuentes históricas, parte del actor principal (ego), y en orden de cercanía, a los miembros del grupo. Algunas de estas interrogantes son: quiénes son los actores, informantes y vínculos clave; cuáles son los actores cercanos, intermedios y lejanos; qué fines persiguen; cuál fue su formación social, económica, política, cultural, comercial; cómo llegaron al punto histórico que se analiza; qué clase de vínculos tienen los miembros de la red; con quiénes y cómo se relacionaron para un fin específico; qué medios de información y recursos materiales tenían para llegar a sus metas; quiénes son los actores o grupos rivales o en pugna.

Para crear la imagen de la red a estudiar, las respuestas son interpretadas por el grado y tipo de relación entre los implicados, en una matriz relacional del sistema computacional Ucinet 6.499 donde 0 (cero) representa un vínculo nulo, y 1 (uno) significa una relación de determinada clase. Concluido el proceso de captura, se aplicó un programa vinculado al de Ucinet: NetDraw 2.136, el cual permite la visualización de las redes establecidas entre los actuantes (grafo). ${ }^{3}$

La historia es considerada en relación con los marcos de las ciencias humanas y experimentales, el reto está en reducir la brecha de estos ámbitos del saber para unir humanismo, ciencia y tecnología. Como parte

${ }^{2}$ Por red social se entiende como un mapa de todos los lazos relevantes entre los actores o nodos estudiados, el análisis de las redes pueden ser "egocéntricas" o "completas", en ellas se trata de identificar la red que envuelve a una o más personas en los diferentes contextos sociales en los que interactúan. Por lo tanto, se utiliza el concepto para denotar conjuntos complejos de relaciones entre miembros de los sistemas sociales en todas las dimensiones, desde el ámbito interpersonal hasta el internacional. Es decir, las redes no están determinadas por normas económicas y formas culturales que regularían su funcionamiento. No se mitifican sino que más bien se construyen a partir de la observación empírica de los vínculos familiares, de paisanaje, de negocios y de clientela que forman precisos actores o cuerpos sociales.

${ }^{3}$ La descarga de los programas computacionales Ucinet y NetDraw se realiza desde http:// www.analytictech.com 
de esta búsqueda, en nuestro artículo se utilizaron estas herramientas interpretativas y computacionales como los medios para conectar el mundo de los actores implicados en 1799, durante el juicio de comiso librado por el corsario francés Juan Chevallier, quien al ser aliado de los españoles obtuvo del intendente de Yucatán Arturo O’Nelly una patente de corso. Zarpando desde el puerto de Campeche requisó dos barcos neutrales de pabellón estadunidense que poseían registros de carga simulados. Con ello se perciben los efectos negativos del conflicto bélico en el dominio de España en el mar, las tensiones y alianzas comerciales entre españoles, franceses y estadunidenses en el Caribe durante las guerras navales, además de establecer los vínculos sociales y mercantiles entre grupos privados de vigilancia naval y comerciantes de diversas nacionalidad en el Caribe novohispano.

\section{AlianZa entre España y Francia en las guerras naVales: SUS CONSECUENCIAS EN NUEVA ESPAÑA}

El 16 de agosto de 1796, en San Ildefonso, se firmó el Tratado de Alianza Ofensiva y Defensiva entre su Majestad Católica y la República Francesa; ${ }^{4}$ con ello, España se alió con su otrora enemiga, significando la unión de recursos materiales y económicos, principalmente las fuerzas militares terrestres y navales que ambas potencias poseían. ${ }^{5}$ En su artículo XI se lee:

Si fuesen o llegasen a ser insuficientes dichos socorros las dos potencias contratantes pondrán en movimiento las mayores fuerzas que les fuera posible, así como de mar como de tierra, contra el enemigo de la potencia atacada, la cual usará de dichas fuerzas, bien combinándolas, bien haciéndolas obrar separadamente, pero todo conforme a un plan concertado entre ambos. ${ }^{6}$

Con esta unión la armada hispano-francesa superaba a los británicos con respecto al número de bajeles de guerra (véase gráfica 1); ello dio el incentivo final para que Carlos IV abandonara su política de no agresión frente a Inglaterra, aunque le convenía la paz. La decisión de romper la

${ }^{4}$ Tratado de Alianza Ofensiva y Defensiva entre su Majestad Católica y la República Francesa (San Ildefonso, España, 16 de agosto de 1796). (Reales Cédulas, vol. 166, exp. 99). Archivo General de la Nación, México.

${ }^{5}$ Tratado de Alianza Ofensiva y Defensiva entre su Majestad Católica y la República Francesa (San Ildefonso, España, 16 de agosto de 1796). (Reales Cédulas, vol. 166, exp. 99, fs. 132142v). Archivo General de la Nación, México.

${ }^{6}$ Tratado de Alianza Ofensiva y Defensiva entre su Majestad Católica y la República Francesa (San Ildefonso, España, 16 de agosto de 1796). (Reales Cédulas, vol. 166, exp. 99, f. 135v). Archivo General de la Nación, México. 


\section{GRÁFICA 1. BARCOS MILITARES DE ESPAÑA, FRANCIA E INGLATERRA EN 1796}

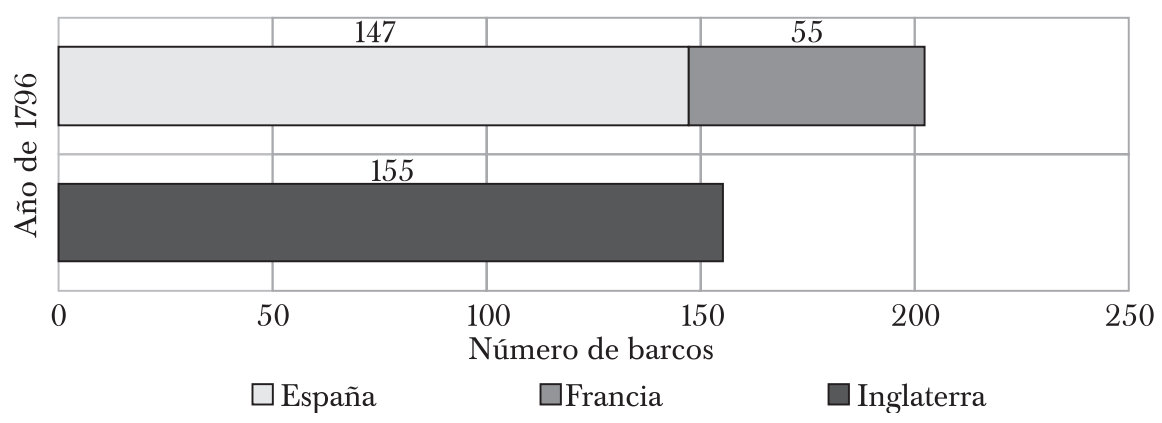

Fuente: elaboración propia con base en Bajeles bélicos de la marina de España. Francia e Inglaterra (1796-1808). Museo Naval de Madrid. Fuerza Naval Española. España. Instituto Virtual Cervantes. Recuperado de http://cvc.cervantes.es/actucult/museo_naval/sala4/navios/

alianza de dos años con el rey Jorge IV obedecía principalmente a razones económicas, pues los ingleses practicaban el contrabando y requisaban barcos con pabellón español en territorios americanos, entorpeciendo el comercio entre España y las Indias Occidentales. Así, el 7 de octubre de 1796 España declaró la guerra a Inglaterra, ${ }^{7}$ acontecimiento conocido como primera guerra naval (1796-1802); después tuvo un cese de hostilidades -Paz de Amiens, 1802-1804-, y su continuidad en la segunda guerra naval, 1804-1808 (Fisher, 1993, p. 45; Hernández, 1992, p. 267).

Pero el número no era garantía de victoria, pues a pesar de encontrarse en inferioridad numérica, la superioridad técnica, la disciplina y el entrenamiento de los miembros de la marina real británica demostraron su valía, condiciones que la convertían en un arma de guerra casi imbatible contra las fuerzas navales franco-españolas, situación que se apreció a unos meses del inicio del conflicto con las derrotas subsecuentes de la flota aliada. Por citar las más relevantes: la del 14 de febrero de 1797, en el cabo de San Vicente; las batallas del Nilo, el 1 y 2 de agosto de 1798; la del 7 de julio de 1801, en Algeciras, y el punto culminante el 21 de octubre de 1805, día en que 27 navíos ingleses se enfrentaron contra 34 bajeles franco-españoles en el cabo de Trafalgar, saliendo victoriosos los primeros

${ }^{7}$ Tratado de Alianza Ofensiva y Defensiva entre su Majestad Católica y la República Francesa (San Ildefonso, España, 16 de agosto de 1796). (Reales Cédulas, vol. 166, exp. 99, f. 135v). Archivo General de la Nación, México. 
y asentando su superioridad en los mares para todo el siglo XIX (Castillo, 1992, pp. 193-197; Hernández, 1992, p. 316).

Durante las guerras navales, el Caribe -que abarca las cuencas del Golfo o Seno Mexicano, el arco de islas conocidas como Antillas Mayores y Menores, hasta las costas continentales de los que hoy es Venezuela (Grafenstein, 1997, p. 14)- fue escenario de una lucha de España y Francia contra Inglaterra por mantener el control político y económico. Casi desde el principio de las hostilidades los territorios españoles fueron acosados por la marina inglesa; en febrero de 1797, una escuadra inglesa, conducida por sir Ralph Abercromby, logró la rendición de las fuerzas españolas de la isla de Trinidad; en abril de ese mismo año, Abercromby intentó fallidamente conquistar Puerto Rico (Zapatero, 1964, pp. 61 y 146-150). A pesar de haber fracasado, la flota británica representó un gran contingente que puso en alerta las rutas y bases comerciales americanas; además, el factor riesgo supuso un descenso en las salidas de barcos mercantes españoles, pues la posibilidad de caer en manos enemigas era alta. Ejemplo de ello es la carta del virrey de Nueva España, marqués de Branciforte, del 3 de julio de 1797 informando al ministro Pedro Varela que "tan pronto se declaró la guerra a Inglaterra han llegado a las costas del Seno Mexicano barcos enemigos [...] apresando todo barco que sale de Veracruz [...] muchos más tenían miedo de salir del puerto". ${ }^{8}$ Por ende, se dio una crisis en el comercio, pero lo más representativo fue con la derrota de la armada española en el cabo San Vicente, en abril de 1797, pues el almirante británico, Horacio Nelson, estableció un cerco en el puerto gaditano, lo cual paralizó los intercambios (Fisher, 1993, pp. 45-46; Lucena, 1990, p. 599) (véase cuadro 1).

La consecuencia del bloqueo representó una baja sustantiva en las transacciones mercantiles veracruzanas: sus importaciones cayeron 92\% y las exportaciones a España descendieron 97\%. Para Nueva España esto acarreó problemas económicos, como la escasez y la especulación de productos europeos. Ante esta situación las quejas fueron casi inmediatas, como la presentada en agosto de 1797 por el virrey marqués de Branciforte: "y recayendo la que queda en pocas manos pudientes y abarcadoras que excitadas por la codicia de exorbitantes ganancias dan la ley a los precios con graves e irreparables perjuicios al público consumidor" (Fisher, 1993, p. 46).

Otros puertos americanos se hallaron en situaciones similares. En La Guaira, el número de buques que salió para España descendió de 40 (en 1796) a 28 (en 1797) -la mayoría zarpó antes de la llegada de la noticia del

${ }^{8}$ [Marqués de Branciforte a Pedro Varela] (3 de julio de 1797). Ministerio de Cultura (Legislación Histórica Español, Indiferente General, vol. 2466, leg. 1034). Archivo General de Indias, España. Recuperado de http://www.mcu.es/archivos/lhe/ 
CUADRO 1. COMERCIO DEL PUERTO DE VERACRUZ, 1796-1799

\begin{tabular}{crc}
\hline Año & Importaciones (en pesos) & Exportaciones (en pesos) \\
1796 & 6549825 & 7304342 \\
1797 & 520472 & 238649 \\
1798 & 1799000 & 5510400 \\
1799 & 2230400 & 6311500 \\
\hline
\end{tabular}

Fuente: elaboración propia con base en de Fisher (1993, p. 46); Ortiz (1978, p. 264), y Souto (2001, pp. 145-149).

bloqueo británico-, y entraron sólo siete desde la península; en Buenos Aires estaban atrapados 33 buques, pues ya no querían organizar convoyes a pesar de tener a su disposición dos fragatas y una corbeta de guerra, lo anterior porque algunos barcos enemigos habían sido vistos en la boca del río. Representación de este desfavorable panorama es la advertencia en julio de 1797 que da el virrey del Río de la Plata, Antonio Olaguer Feliú y Heredia López y Domec, a los capitanes de los buques del puerto de Montevideo: "de la imposibilidad de entrar en el puerto de Cádiz u otro de la península con seguridad mediante hallarse el primero bloqueado por una escuadra inglesa y los demás infestados de corsarios de la misma nación" (Fisher, 1993, p. 46).

De entre las medidas que el gobierno español tomó para reactivar el comercio transatlántico fue la concesión de flete en buques neutrales y, para dar seguridad a las rutas, la autorización a corsarios españoles y de sus aliados franceses a patrullar los mares. Si bien se logró cumplir con lo esperado, se dieron efectos negativos en el escenario económico y político del imperio.

\section{POR GRAVE NECESIDAD: EL USO DE BUQUES NEUTRALES Y REGISTROS SIMULADOS EN EL CARIBE ESPAÑOL}

En materia de comercio, grave necesidad era una frase de justificación para la época (sea como explicación de ser perseguido por algún enemigo o por el mal tiempo) a fin de que se le autorizara al buque atracar en puerto no autorizado, o bien, un alegato de individuos atrapados en actos de 
contrabando. ${ }^{9}$ Pero la corona española también llegó a verse obligada a realizar actos por grave necesidad, si bien no lo decía abiertamente como sus vasallos, sí lo manifestaba en sus políticas tomadas.

En las guerras navales, al verse afectado el comercio ultramarino por grave necesidad, el gobierno español estableció medidas extraordinarias entre las que estuvieron dos que sustentan este artículo. Uno, la concesión de flete a barcos neutrales y, dos, la concesión a esos navíos de dobles registros simulados; el primero fue un medio para reactivar las transacciones y el segundo una forma de protegerlas del enemigo inglés durante las travesías marítimas. Analicemos las consecuencias de ambas medidas en el comercio, la política y la diplomacia de España.

Debido al riesgo en alta mar, los agentes comerciales de Nueva España arrendaron crecientemente el uso de barcos sueltos neutrales, ${ }^{10}$ como lo demostró el virrey Miguel de la Grúa Talamanca y Branciforte, quien a un mes del bloqueo gaditano informó al rey en carta del 24 de mayo de 1797 que "los que hacen comercio en aguas del Seno [Mexicano] por grave necesidad han preferido el uso de barcos angloamericanos [...] quienes por hallarse en calidad de neutrales de la presente guerra llegan a puertos en que nuestros bajeles son acosados por el enemigo". ${ }^{11}$

El uso de buques neutrales en forma irregular obligó a la corona española a oficializar la práctica (Fisher, 1993, p. 102). Así, por Real Cédula del 18 de noviembre de 1797, se autorizó que barcos de naciones imparciales ejercieran el comercio con el imperio, a condición de que zarparan desde puertos hispanos, con cargas autorizadas y descargaran en fondeadero español. Mas tal medida fue ampliada a poder zarpar de puerto neutral pero con tornaviaje hacia España (Souto, 2001, pp. 180-181). Así, buques neutrales llevaron a territorios novohispanos manufacturas predominantemente textiles ingleses, franceses y alemanes, así como vinos y herrajes, exportando desde Veracruz plata, grana cochinilla, azúcar, algodón, entre otros (Ortiz, 1978, pp. 163-167).

A raíz de la apertura comenzaron a arribar a la América española bajeles daneses, suecos y hanseáticos. No obstante, fueron los estadunidenses

${ }^{9}$ A lo largo del ramo Marina del Archivo General de la Nación, México, el lector podrá encontrar el uso de la "grave necesidad" en expedientes sobre temas de arribadas forzosas, el contrabando, el no pago de impuestos, el realizar tratos con los enemigos de la corona española, entre otros.

${ }^{10}$ Hacemos mención del término barcos sueltos neutrales porque esta clase de navíos no seguían derroteros específicos, pero sí tenían atracaderos de salida y arribo establecidos, lo cual era una situación similar a la de los barcos de registro españoles, la única diferencia es el pabellón bajo el que navegaban.

${ }^{11}$ [Carta del el virrey Miguel de la Grúa Talamanca y Branciforte] (24 de mayo de 1797). (Correspondencia de Diversas Autoridades, vol. 56, exp. 2, fs. 26v-28). Archivo General de la Nación, México. 
los que obtuvieron los mayores beneficios (Grafenstein, 1997, pp. 215-216). Ello porque además de la cercanía territorial, ellos tenían un tratado comercial previo conocido como Pinckney o de Amistad, Límites y Navegación (o también Tratado de San Lorenzo), firmado el 27 de octubre de 1795 por Thomas Pinckney, ministro de dicha nación y el duque de Alcudia, Manuel de Godoy y Álvarez de Faria, secretario del Despacho Universal de Carlos IV. Este tratado daba fin a una larga contienda iniciada con la independencia de Estados Unidos, asegurando para los ciudadanos de esa nación libre comercio a territorios hispanoamericanos, y que representaron un ávido mercado durante las guerras imperiales que acaecieron entre 1797 y 1808 (Brinkley, 2004, pp. 175-177).

Carlos Marichal (2000) destaca que entre 1797 y 1799, de los "56 barcos neutrales que arribaron a Veracruz, 44 eran estadunidenses, pasando las exportaciones de estos últimos a Hispanoamérica de 1000000 de dólares en 1796 a un promedio anual de 10000000 de dólares entre 1799 y 1801" (p. 168). Mientras que los buques sueltos con pabellón español fueron menos requeridos, por ejemplo, en agosto de 1798, de los 23 barcos mercantes que atracaron en el puerto de Campeche, sólo cinco fueron españoles, el resto eran de pabellón neutral, de los cuales catorce eran estadunidenses. ${ }^{12}$ Esto da una idea de la creciente importancia de los buques estadunidenses para las exportaciones novohispanas del Seno Mexicano, quienes aseguraban una rápida y segura venta en algún otro puerto americano sin arriesgarse a llevarlo por las peligrosas rutas trasatlánticas.

La preferencia de los españoles por los barcos estadunidenses se dio no sólo para subsanar la falta de buques mercantes, sino por ser imparciales no existía "riesgo" aparente, ya que las naciones neutrales, al mantenerse en teoría al margen de los conflictos entre España e Inglaterra, las incursiones enemigas no se aplicaban, evitándose la pérdida de la embarcación o mercancías, haciendo más seguro el tránsito en alta mar (Marichal, 2000, p. 168). Esta predilección perjudicó el sistema español, por lo que los consulados de Cádiz y Barcelona presionaron para cancelar la concesión a los neutrales, logrando derogarla por real orden del 20 de abril de 1799, publicándose en Nueva España el 2 de septiembre de $1799 \cdot{ }^{13}$ El 18 de julio de 1800 y el 11 de agosto de 1801 se continuaron dando órdenes para erradicar el comercio con neutrales, lo que demuestra que se trataba de una ley que se acató pero no se cumplió (Marichal, 2000, pp. 171-173; Villalobos, 1965, pp. 83-84). La desobediencia radicó en que los barcos neutrales

\footnotetext{
${ }^{12}$ Registros de carga (Agosto de 1798). (Marina, vol. 107, exp. 4, fs. 168-189v). Archivo General de la Nación, México.

${ }^{13}$ Registros de carga (2 de septiembre de 1799). (Bandos, vol. 20, exp. 40, f. 131). Archivo General de la Nación, México.
} 
podían llevar la mercancía con menor riesgo, además de que los navíos españoles no tenían la capacidad para hacer frente a las necesidades del imperio, tal como nos lo hace constar un funcionario español que increpaba la derogación: "¿Cómo hubiera podido subsistir la isla de Cuba si en el año de [17]98 se hubieran quedado en La Habana 134000 caxas de azúcar que extrajeron los neutrales. $\mathrm{O}$ en palabras de un anónimo 'la ley de la necesidad es superior a todas las leyes'." ${ }^{14}$

Con la Paz de Amiens, firmada el 26 de marzo de 1802, se puso fin a la primera guerra naval; al no existir riesgo de ser apresados, se canceló el comercio neutral. Esto fue aprovechado por los agentes comerciales del imperio; por ejemplo en Barcelona y Cádiz se dio salida a los productos acumulados a bordo de buques españoles (Fisher, 1993, pp. 76-77). El 20 de abril de ese mismo año llegaron al puerto de Veracruz los primeros avisos del cese de hostilidades y casi de inmediato comenzaron a suspender los permisos hacia barcos neutrales; por ejemplo, en carta del 12 de mayo de 1802, las autoridades novohispanas se dan por enteradas sobre la cancelación de flete con neutrales. Lo que representó el descenso de las transacciones de las casas comerciales estadunidenses con las posesiones españolas del Caribe. ${ }^{15}$

Con la publicación de la real orden del 24 de diciembre de 1804, España y Francia declararon de nueva cuenta la guerra a Gran Bretaña, iniciando la segunda guerra naval (1804-1808). Para los circuitos comerciales marítimos del imperio español las consecuencias fueron similares al primer conflicto: bloqueos a los puertos y riesgos de apresamiento de los buques. Por ende, en Real Cédula del 9 de agosto de 1805 se autorizó el uso de neutrales, permitiendo que casas comerciales como las de Ámsterdam, Hamburgo, Filadelfia, Nueva York, Boston y Baltimore tuvieran intercambios con los dominios del rey católico, en mayor medida con los puertos de Caracas, La Habana, Montevideo y Veracruz. La concesión permitió a todo bajel neutral comerciar desde puerto imparcial o español y dirigirlo hacia otro atracadero similar, ello con la condición de que las autoridades españoles acreditaran la carga y los buques se dirigieran sólo a los puertos que los registros tenían señalados, pero estas cláusulas cambiaron a fines de 1805 (Marichal, 2000, p. 170, y Souto, 2001, pp. 190-192).

El 21 de octubre de 1805, en el cabo de Trafalgar, España, se llevó a cabo una de la más importantes batallas navales del siglo XIX, en la cual España y Francia perdieron 23 buques de guerra y otorgó a la victoriosa

${ }^{14}$ [Carta de Mendinueta a Miguel Cayetano Soler] (19 de febrero de 1799). Ministerio de Cultura (Legislación Histórica Española, Indiferente General, leg. 2467). Archivo General de Indias, España. Recuperado de http://www.mcu.es/archivos/lhe/

${ }^{15}$ Aviso de cancelar permisos a neutrales (abril-mayo, de 1802). (Correspondencia de Diversas Autoridades, vol. 60, exp. 77, fs. 201-202, 204). Archivo General de la Nación, México. 
armada británica el control del Atlántico por todo el resto de la centuria (Fisher, 1993, p. 64). Ante la derrota, las rutas ultramarinas quedaron más sensibles a los ataques británicos, por lo que el 16 de junio de 1806 se autorizó a cualquier buque que saliera de España hacer escala y descargar donde le pareciera conveniente y dar por concluido su registro donde más les acomodase. Para el 10 de agosto se permitió reexportar cualquier mercancía a otros puertos sin importar la nacionalidad. ${ }^{16}$ Estas medidas representaron la pérdida del control de la corona pues ya no tenía manera de regular los intercambios marítimos. En el puerto de Veracruz, en 1806, 1807 y 1808 , del total de sus importaciones, el comercio neutral representó $48.84,60.53$ y $48.2 \%$, respectivamente, de los cuales poco más de $70 \%$ correspondía a navíos estadunidenses (Ortiz, 1978, p. 233).

Con el fin de la segunda guerra naval, el 30 de noviembre de 1808, se intentó erradicar el uso de barcos neutrales, lo cual no se logró, pues la desobediencia en las colonias se extendió hasta las altas autoridades. Por ejemplo, las reales órdenes del 17 y 21 de marzo de 1809, promulgadas por la Junta Central, prohibían la entrada de buques extranjeros y neutrales en puertos americanos, así como continuar con el cobro arancelario sobre los cargamentos que arribaran a puerto. La reacción del capitán general de Cuba, como la de sus homólogos de Veracruz, Caracas y Buenos Aires, fue su respuesta conjunta del 9 de mayo donde habían decidido "admitir buques y frutos extranjeros internamente [...] y se sacaría géneros cubanos a puertos extranjeros sin el pago de derechos". ${ }^{17} \mathrm{El}$ capitán general de Yucatán permitió desde 1808 a "los comisionados de las islas inglesas de Barbados que establecieran sus negociaciones mercantiles", ello para evitar "un estado de desesperación" ${ }^{18}$ España como eje de control político sobre el comercio de Nueva España había dejado de existir. El hecho que la Real Armada española fuera derrotada en Trafalgar dificultó el tráfico comercial, así como el control de las colonias, con lo que, sumado la preferencia de bajeles neutrales, se facilitó la autonomía americana iniciada en 1810 (Rodríguez, 2007, pp. 16-18).

Como puede observarse, comerciantes y gobierno intentaron a toda costa mantener abiertas las líneas mercantiles interoceánicas, ya sea a

\footnotetext{
${ }^{16}$ Autorización (16 de junio de 1806). (Reales Cédulas Originales, vol. 196, exp. 156, f. 195). Archivo General de la Nación, México.

${ }^{17}$ [Causa formada a los autores de la Real Orden de 17 de mayo de 1810 sobre comercio activo en las Américas por los extranjeros] Ministerio de Cultura (Legislación Histórica Española, Indiferente General, legajos 2463-2465). Archivo General de Indias, España. Recuperado de http://www.mcu.es/archivos/lhe/

${ }^{18}$ [Causa formada a los autores de la Real Orden de 17 de mayo de 1810 sobre comercio activo en las Américas por los extranjeros] Ministerio de Cultura (Legislación Histórica Española, Indiferente General, legajos 2463-2465). Archivo General de Indias, España. Recuperado de http://www.mcu.es/archivos/lhe/
} 
través de barcos sueltos españoles o neutrales, pero existía otra manera de intentar burlar al enemigo inglés y este era el uso del doble registro de simulación.

En teoría, durante un conflicto bélico las naciones en guerra no podían requisar embarcaciones con pabellón neutral, salvo en los casos de comprobarse de que el bien incautado pertenecía a uno de los enemigos, o que lo transportado estaba fuera de registro, o lo que es igual, contrabando. Por citar un caso: el 12 de enero de 1799, el bergantín guardacostas novohispano El Volador revisó la escotilla mayor de la goleta neutral angloamericana Cenit, la cual zarpó de Veracruz hacia Cádiz con permiso de frutos y efectos, hallando "varios sacos, piezas sueltas, un baúl y otras cosas" no registradas, siendo incautadas y conducidas a puerto. ${ }^{19}$

Por ello, durante las guerras navales ante los peligros de incautación por embarcaciones inglesas, los comerciantes españoles y las compañías mercantiles estadunidenses para eludir el peligro utilizaron el doble registro de simulación. En Nueva España esta clase de documento basó su efectividad en dos situaciones: primero, el transporte de mercancías españolas en barcos con pabellón neutral y, segundo, la concesión del gobierno de su majestad católica a poder trasladar desde un atracadero español sus productos hacía un puerto de nacionalidad no beligerante.

Bajo el amparo de su neutralidad, las compañías estadunidenses solicitaban a las autoridades de puerto español un registro simulado, consistente en un registro "simulado" de carga falsa escrito en idioma inglés con datos para aparentar que los productos eran propiedad de estadunidenses y que la embarcación tenía como destino un puerto de Estado Unidos de América, y otro registro (el auténtico) escrito en castellano donde se aseveraba que los géneros eran de españoles y serían llevados hacía un atracadero del imperio español. Esto a fin de engañar a los británicos, pues en caso de ser abordados por ellos, se presentaría el documento falso, y si la revisión la hacía uno de pabellón francés o español, se mostraba el verdadero, y de esta manera asegurar que los productos llegaran a su destino.

Para los registros simulados de la metrópoli hacia América (véase cuadro 2), Robert Fisher (1993, p. 62) ubicó en el Archivo General de Indias, un "registro de navegación extranjero y otras precauciones y escala en puertos neutrales de América para simular la propiedad y evitar en lo posible los riesgos que en esta guerra por sus circunstancias tiene la navegación con neutrales", del 23 de abril de $1798 .^{20}$

\footnotetext{
${ }^{19}$ Juicio de Comiso (12 de enero de 1799). (Marina, vol. 139, exp. 1, fs. 1-10v.; exp. 2, fs. 1128; exp. 3, fs. 29-87). Archivo General de la Nación, México.

${ }^{20}$ [Carta de Mendinueta a Miguel Cayetano Soler] (19 de febrero de 1799). Ministerio de Cultura (Legislación Histórica Española, Indiferente General, leg. 2467). Archivo General de Indias, España. Recuperado de http://www.mcu.es/archivos/lhe/
} 


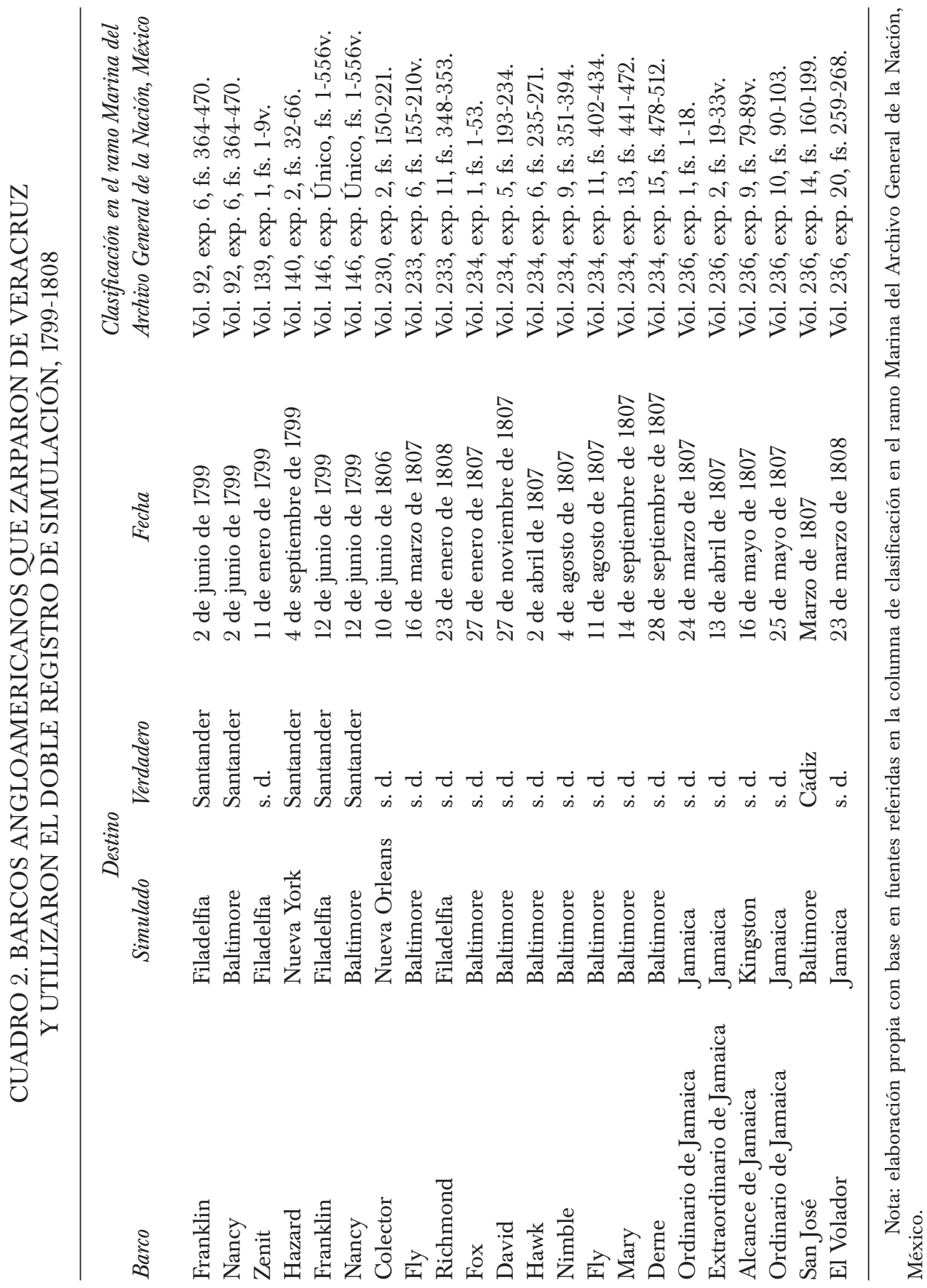


El doble registro tiene su ocaso con la emancipación de Nueva España, ya que al convertirse en una nación independiente los conflictos entre España e Inglaterra ya no repercutían directamente en sus transacciones comerciales. El uso de buques neutrales complementados con los dobles registros de simulación fueron medios concedidos por el gobierno español para que el comercio ultramarino continuara a toda costa, pero también poseía medios defensivos para vigilar las rutas y las costas de posibles ataques enemigos, entre ellos el uso de corsarios.

\section{UNIÓN DEL CORSO ESPAÑOL Y FRANCÉS DURANTE EL CONFLICTO NAVAL}

El corso marítimo nace en la Edad Media como actividad naval efectuada por los particulares en tiempos de guerra, y España lo utilizó de forma defensiva para salvaguardar las costas de su imperio. Si una persona quería ejercer el corso, debía obtener una patente la cual consistía en una autorización real para que un particular tuviera la facultad de poder decomisar las propiedades enemigas y el contrabando, sirviéndole como certificado oficial de represalia, de garantía de buen comportamiento, y en caso de ser apresado ser tratado como prisionero de guerra, en caso de no contar con la patente, toda actividad corsaria era ilegítima y por ende considerada pirata (Azcárraga, 1950, pp. 28-29; Cruz, 2013, p. XI; Lucena, 1992, pp. 246-247).

Durante los siglos XVI y XVII sólo el rey español podía otorgar patentes, pero desde 1714 por Real Cédula del 30 de marzo, pudieron ser expedidas también por los virreyes, presidentes, gobernadores, capitanes generales y posteriormente intendentes. ${ }^{21} \mathrm{~A}$ menudo, este documento incluía una introducción de la ordenanza vigente, seguida por la información sobre pruebas de solvencia del solicitante, el nombre de la nave que quería utilizar, el número de tripulación, y el compromiso de comportarse conforme a las reglas de mar, absteniéndose de no requisar naves españolas, aliadas o neutrales, salvo en los casos de irregularidades (Stapells, 1992, p. 13). Además, era legal que un corsario obtuviera múltiples patentes de diversas demarcaciones políticas, aunque no era común dado el costo por licencia. Sin embargo, la posesión de varias patentes permitía ampliar el radio de acción; por ejemplo, Benito Socorrras quien entre junio y julio de 1720 solicitó y obtuvo patentes de los gobernadores de Cartagena de Indias,

${ }^{21}$ Real Cédula. (30 de marzo de 1714). (Reales Cédulas Originales, vol. 36, exp. 107, fs. 307$307 v)$. Archivo General de la Nación, México. 
Santiago de Cuba, Baracoa y de Santo Domingo ${ }^{22}$ (véase también Stapells, 1992, p. 14).

Para obtener una patente se requería el abono de una fianza, esta servía como depósito de cobranza en caso de incurrir en faltas como acciones de piratería, perjuicio a embarcaciones aliadas y neutrales o falsedad de testimonios, entre otros. ${ }^{23}$ En caso de que el dueño o capitán de la embarcación no contara con la cantidad requerida, se asociaba con un armador, por lo regular un pudiente comerciante quien, con la esperanza de obtener del decomiso una ganancia, aportaba el capital para cubrir la fianza, el avituallamiento de pertrechos de guerra y de comestibles adquiridos en los reales almacenes, así como el reclutamiento inicial de la tripulación del navío (Lucena, 1992, pp. 247-255).

Según la ordenanza de corso vigente, casi siempre en los artículos segundo y tercero se estipulaba que con la patente, el comandante militar de Marina de la provincia facilitaría hombres y pertrechos en caso de necesitarse, pero también el capitán o armador contrataban a hombres. Una vez habilitado, el buque tenía permiso para patrullar, con la legitimidad de poder atacar y requisar barcos enemigos, y en bajeles de su nación, aliados o neutrales, examinar que estuvieran en orden los pasaportes, los registros de carga y certificados de impuestos de salida portuaria, no llevar contrabando; en caso de encontrar alguna irregularidad, el barco, la carga y los tripulantes eran declarados como presa y conducidos a puerto para abrir un proceso judicial que legitimara las incautaciones (Cruz, 1997, p. 454; Stapells, 1992, p. 23).

Ya en puerto, las embarcaciones y las cargas sospechosas de ser "buenas presas", eran puestas a disposición del Tribunal de Comisos facultado para llevar a cabo juicios de similar nombre, el personal estaba compuesto por los ministros de Marina e incluso por el gobernador e intendente. En caso de ser hallado culpable se incautaban las mercancías e inclusive su barco, los cuales eran puestos a disposición de las autoridades de la Real Hacienda para ser rematados en almoneda pública. ${ }^{24}$ La distribución de lo subastado se repartía entre las autoridades gubernamentales y los corsarios implicados en la aprensión, los porcentajes estaban determinados por el Reglamento de Comisos de Tierra, de Mar y Mixtos; el objetivo de la normativa era lograr un mayor incentivo económico para que más particula-

\footnotetext{
${ }^{22}$ Testimonio de Patentes (junio a julio de 1720). (Contaduría, leg. 1064, ramo 6).

${ }^{23}$ Artículo primero de la Ordenanza de Corso de 1796 (12 de octubre de 1796). (Correspondencia de Virreyes: Marqués de Branciforte, vol. 186, s. exp. fs. 223-224v). Archivo General de la Nación, México.

${ }^{24}$ Artículo LI de la Ordenanza de Corso de 1796 (12 de octubre de 1796). (Correspondencia de Virreyes: Marqués de Branciforte, vol. 186, s. exp. f. 252v). Archivo General de la Nación, México.
} 
res prestasen naves para combatir al enemigo y el comercio fraudulento. ${ }^{25}$ Las bonificaciones otorgadas a los corsarios se repartían según el escalafón del armador, el corsario y su tripulación. La motivación económica sale a relucir, y a partir de ella se dio la estructura del corso español (véase diagrama 1).

En el Caribe, los corsarios españoles salían en búsqueda de presas y la corona obtenía una fuerza de vigilancia y ataque, además esta clase de patrullaje también podía realizarse con corsarios aliados, como fue el caso de los franceses. Como ya vimos en páginas anteriores, en su intento por detentar la hegemonía en los mares, España y Francia firmaron el Tratado de Alianza Ofensiva y Defensiva entre su Majestad Católica y la República Francesa de 1796, en él se lee:

Artículo decimotercero: Cuando las dos partes llegasen a declarar la guerra de común acuerdo a una o más potencias, porque las causas de las hostilidades fuesen perjudiciales a ambas; no tendrán efecto las limitaciones prescritas en los artículos anteriores, y las dos potencias contratantes deberán emplear contra el enemigo común todas sus fuerzas de mar y tierra. Y concertar sus planes para dirigirlos hacia los objetivos más convenientes, bien separándolas o bien reuniéndolas (Castillo, 1843, p. 673).

Bajo esta cláusula ambas naciones unieron sus armadas y, por lo tanto, sus corsarios contra el enemigo común: Inglaterra, tal y como lo consta la Real Cédula del 29 de enero de 1797. En ella el monarca español dice: "concedo que los aliados puedan tener patente en mis Indias [...] e instruyó las autoridades competentes a que se le auxilie en todo necesario para que se apresten a navegar con mis corsarios por esas aguas". ${ }^{26}$

Respecto a Francia, la autorización que otorgó esta potencia a sus corsarios a solicitar patentes de corso españolas respondía a la tentativa colonial del Directorio y posteriormente del primer cónsul Napoleón Bonaparte, quien vio la necesidad de replantear la cuestión colonial en América a fin de dar a Francia el predominio comercial. El domino francés en el Caribe se basó en la posesión de Santo Domingo, cuyo gobernador tenía la facultad de expedir patentes de corso (Rodríguez, 2000, pp. 75-76). Los franceses podían solicitar patentes de corso francesas en dicha colonia, mas si querían participar en las expediciones de caza en costas novohis-

\footnotetext{
${ }^{25}$ Reglamento de Comisos de Tierra, de Mar y Mixtos (26 de marzo de 1787). (Impresos Oficiales, vol. 53, exp. 20, fs. 361-370v). Archivo General de la Nación, México.

${ }^{26}$ Real Cédula (29 de enero de 1797). (Reales Cédulas Originales, vol. 368, exp. 68, f. 245). Archivo General de la Nación, México.
} 


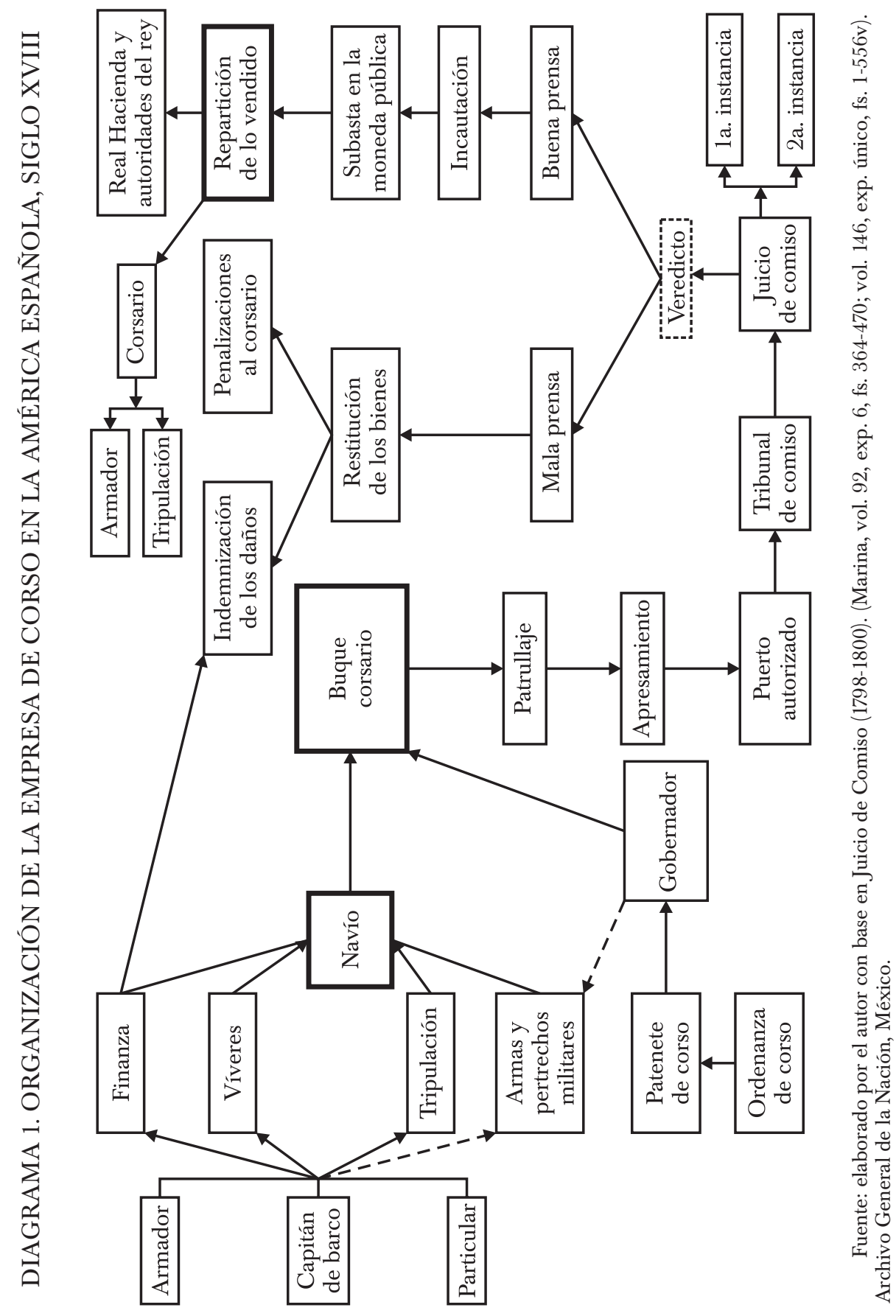


panas, tenían que solicitar una patente española, así como acatar las reglamentaciones -ordenanzas de corso- vigentes en el virreinato.

Como el lector ha podido observar, hubo serias afectaciones en la Carrera de Indias. A través de un estudio de caso presentamos la conjugación del conflicto bélico, la necesidad de recurrir a buques neutrales y dobles registros de simulación, así como la legitimidad y la delgada línea entre piratería y las acciones corsarias conjuntas de españoles y sus aliados franceses.

\section{A LA MAR Y AL ABORDAJE: LA RED DEL CORSARIO FRANCÉS JUAN ChEVAlLIER y SUS PATENTES FRANCESA Y ESPAÑOLA}

Estudiar las relaciones entre los actores de una red (la estructura) ${ }^{27}$ se hace indagando la importancia de los patrones observados dentro del grupo. Estos patrones pueden ser las cuestiones de centralidad (o lo que es similar a qué individuos están mejor conectados con otros) y conectividad (cómo están entrelazados o no unos individuos con otros) (Cachia, 2010, pp. 7-8). Pero las redes no nacen, se hacen y, dependiendo de cómo crezcan, el tipo de red y sus propiedades, estas serán distintas. Como resultado de las diferentes tradiciones históricas, surgieron dos enfoques principales. Por un lado están las redes sociocéntricas (completas), con raíces en la sociología, y definido como análisis de redes sociales, que investiga las relaciones entre diferentes componentes en un grupo, por ejemplo, los actores (instituciones, lugares, personas) dentro de una organización. El segundo enfoque es el de tipo egocéntrica, que surgió del campo de la antropología y es conocida como análisis de redes personales (ARP); tiene por objeto el estudio de la red de un componente o actor específico, frecuentemente con el objetivo de comparar esos datos con el de otras redes personales (Cachia, 2010, p. 7).

Entre los autores que describen el devenir y consolidación del análisis de redes sociales y el análisis de redes personales, así como su metodología, se encuentran Albert László (2002), quien da una introducción amena a la teoría y a sus desarrollos, y Duncan J. Watts (1999), quien da un ejemplo de cómo hacer teoría y aplicaciones en un mismo proceso. Los textos de Alain Degenne y Michel Forsé (2004), y de John Scott (1991), son las mejores introducciones a las redes sociales desde el punto de las ciencias

\footnotetext{
${ }^{27}$ En los estudios de análisis de redes sociales, los términos actor o actores se refieren a los individuos que se encuentran dentro de una red, mientras que los lazos se refieren a las conexiones entre los individuos de una red. El término actor puede aplicarse a una persona concreta, a una institución o una nación.
} 
sociales. En idioma español se cuentan trabajos que dan a conocer las innovaciones en el campo de las redes sociales y los programas informáticos, como los de Daniel Holgado (2010, pp. 106-116), Jorge Gil Mendieta y Samuel Schmidt (2002), José Luis Molina (2004 y 2009), Louise Clark (2006), Óscar Velázquez Âlvarez, Alejandro Aguilar y Norman Gallegos (2005), entre otros.

Los resultados de las redes se representan en forma visual y se conocen como grafos, ${ }^{28}$ los cuales engloban el conjunto de nodos ${ }^{29}$ y sus diversas conexiones, lo que permite realizar estudios de las características formales del entretejido, además de extraer conclusiones simples (cuántos actores intermedios fueron necesarios para conseguir un apoyo), complejas (quién es el agente con más influencia dentro de la red a partir de los contactos). Los datos derivados del estudio y representación gráfica de la red permiten establecer por qué se dan y la clase de nexos existentes entre los actores (Merelo, 2004, p. 1).

Estudiar a Juan Chevallier es indagar en la vida de un corsario que participó en las guerras navales, aliado de España pero influenciado por la Francia revolucionaria, ávido empresario dispuesto a todo, incluso a violentar buques neutrales estadunidenses. Esto último puso en marcha una serie de eventos que sacó a relucir la estructura mercantil y una de las formas de asegurar el viaje de las mercancías españolas durante el conflicto en cuestión. Utilizando las herramientas del análisis de redes personales se ha logrado hacer una representación egocéntrica de los lazos clientelares y de distención que Chevallier estableció durante una de sus correrías como corsario en el Caribe de fines del siglo XVIII. Con base en esos nexos se dilucidan las estrategias y la solidaridad para hacer negocios, sea en actividades como el corso o en el comercio ultramarino (véase grafo 1).

Para comenzar con el análisis del grafo veamos quién fue Juan Chevallier. Nacido en 1769 en Rochefort, Francia, logró ser capitán de navío gracias a la tradición marítima de esa pequeña población asentada a orillas del río Charente cuya desembocadura da al mar Cantábrico. En 1799 se le describe como hombre de "treinta años, talla de cinco pies [1.52 m.], pelo y cejas castaño [o canario], nariz regular y afilada, frente larga, ojos castaños, boca mediana, barba redonda y cara lo mismo". ${ }^{30}$

\footnotetext{
${ }^{28}$ De entre los paquetes informáticos de análisis de redes sociales actuales que permiten realizar grafos están: Ucinet 6 y Netdraw: http://www.analytictech.com, Pajek: http://vlado.fmf. uni-lj.si/pub//networks/pajek/, Netminer http://www.netminer.com/NetMiner/home_01.jsp

${ }^{29}$ Los nodos son los actores que en forma punto o figura se interconectan entre sí dando en su conjunto lo que se entiende como red social. Son de diverso tipo: individuos, empresas, unidades colectivas sociales, departamentos en una empresa, agencias de servicio público en la ciudad, puntos geográficos o estados.

${ }^{30}$ Juicio de Comiso (14 de junio de 1799). (Marina, vol. 146, exp. único, f. 351v). Archivo General de la Nación, México.
} 


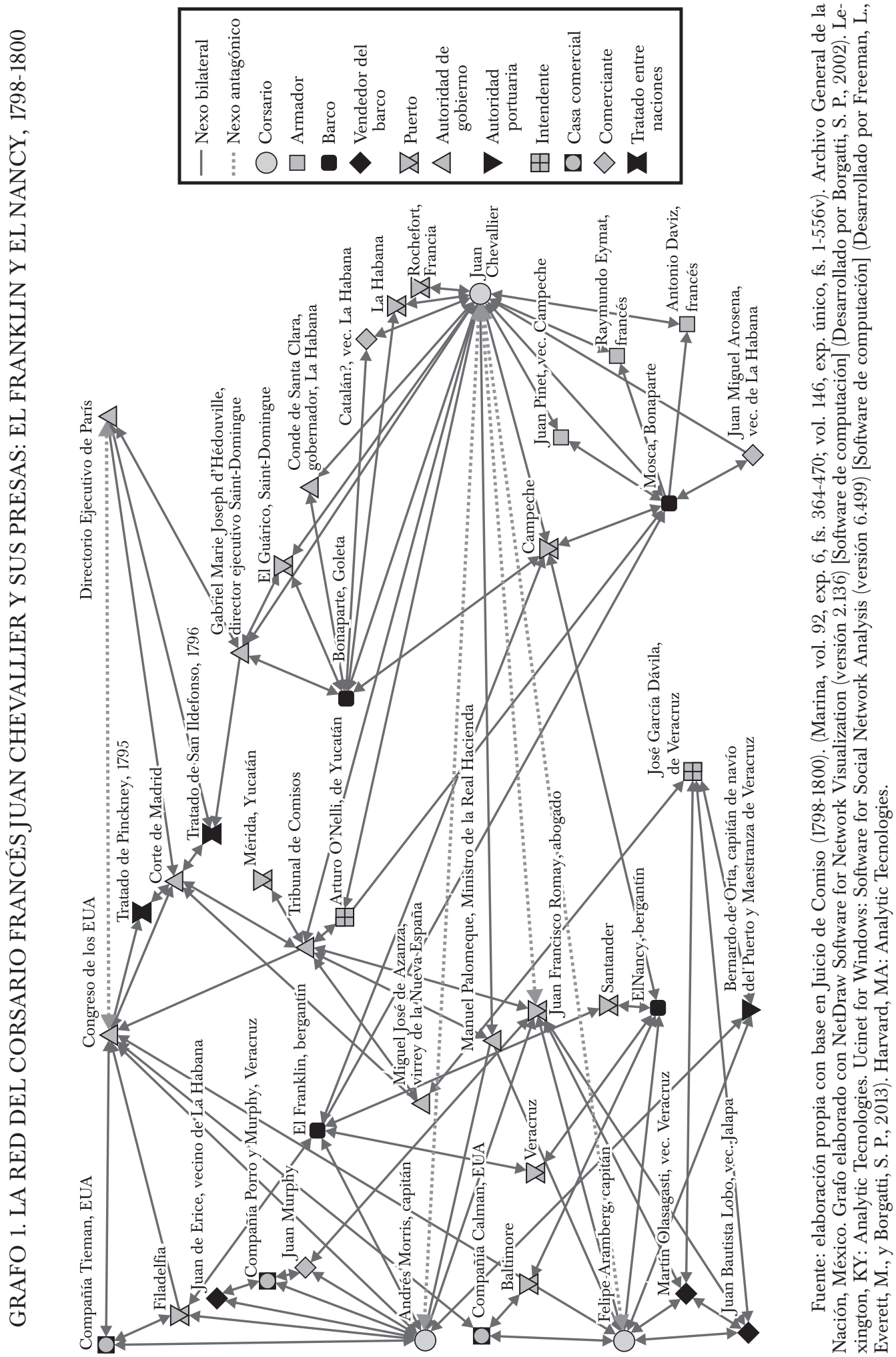


Como se ha visto, en las guerras navales los franceses se aliaron con los españoles al ver la oportunidad de enriquecerse; en 1798, apoyado por el Directorio de la república francesa, Chevallier se traslada a La Habana donde compró al vecino del puerto Juan Miguel Arosena una goleta de 60 toneladas a la cual llamó Bonaparte. Para el 3 de septiembre del mismo año el conde de Santa Clara, gobernador de la isla, le concede un pasaporte español para ir al Guárico. ${ }^{31}$ Esta era una villa portuaria en el noroeste de La Española, que se convirtió bajo el gobierno galo en el principal puerto de su colonia, llamado El Cabo Francés. En octubre, Chevallier mostró su goleta y solicitó una patente francesa al general de división y agente particular del Directorio Ejecutivo de Santo Domingo, Gabriel Marie Joseph d'Hédouville; Chevallier era apoyado por su socio de negocios, su armador, un catalán de nombre desconocido radicado en La Habana, quien dio una fianza de 20000 o 19000 pesos. Para el 23 de octubre el documento solicitado fue entregado con vigencia de seis meses, pertrechos y un armamento principal de once cañones. El 2 de diciembre retornó a La Habana para desde ahí hostilizar al enemigo común de España y Francia: los ingleses. ${ }^{32}$

Puesto que era legal poseer varias patentes y en aras de incrementar las posibilidades de capturar más presas en el Caribe, Chevallier utilizó los estatutos del Tratado de 1796 entre su majestad católica y la república francesa para ser acreedor a los beneficios de la Ordenanza de Corso de 1796, con ello se dirigió a Campeche a ofrecer sus servicios. Se presentó en dicho atracadero como alférez de navío. En mayo de 1799, adquirió de Juan Miguel Arosena, vecino del puerto caribeño, un pequeño buque de 25 toneladas, llamado también Bonaparte y en ocasiones La Mosca, además de su camarilla de armadores: los franceses, Raymundo Eymat, Antonio Daviz y el campechano Juan Pinet; Chevallier presentó una fianza (se desconoce el monto) para solicitar una patente española, pero el gobierno sólo aceptó como armador al vasallo de Campeche. El 4 de mayo el gobernador e intendente de Yucatán, Arturo O’Nelli, firmó el auto de conformidad, recibiendo la fianza y autorizando el equipamiento a La Mosca con tripulación del puerto, suministros, pertrechos y cuatro cañones para salir a vigilar las inmediaciones. ${ }^{33}$

Y fue así como el galo Juan Chevallier, con un grupo de tripulantes campechanos levó anclas en el Seno Mexicano para obtener buenas presas, mas al parecer no reportó que poseía la goleta con patente de corso

${ }^{31}$ Juicio de Comiso (11 de febrero de 1800). (Marina, vol. 92, exp. 6, f. 442; vol. 146, exp. único, fs. 23v., 156, 351v., 391). Archivo General de la Nación, México.

${ }^{32}$ Juicio de Comiso (14 de junio de 1799). (Marina, vol. 92, exp. 6, f. 493; vol. 146, exp. único, fs. 146, 156v., 160-160v., 161, 260, 446). Archivo General de la Nación, México.

${ }^{33}$ Juicio de Comiso (4 de mayo de 1799). (Marina, vol. 146, exp. único, fs. 127v, 136, 162162v., 289, 358, 382, 436v., 442v., 443). Archivo General de la Nación, México. 
francesa, lo cual durante el juicio de comiso librado contra sus aprehensiones (dos bergantines neutrales estadunidenses), le trajo acusaciones de ser un pirata, y tensiones entre los gobiernos de Estados Unidos de América, Francia, la España peninsular y Nueva España.

\section{EL USO DE BUQUES ANGLOAMERICANOS Y SUS REGISTROS SIMULADOS}

Para 1799, gracias al tratado comercial Pinckney, de 1795, y a la necesidad, en 1797, de abrir los puertos españoles a bajeles con pabellón neutral, las casas mercantiles estadunidenses conformaron intrincadas redes personales y comerciales con Veracruz. Así, para el mes de mayo arribaron dos bergantines angloamericanos (Franklin y Nancy), que como se puede observar en el grafo, el capitán del primero era Andrés Morris, arrendado por la compañía Tieman y procedente de Filadelfia. El segundo zarpó desde Baltimore armado con seis cañones, bajo el mando de su capitán Felipe Aramberg y arrendado por la compañía Calman. Ambos desembarcaron sus productos en Veracruz, y se aprestaron a salir con registros de carga verdaderos a España y simulados a Estados Unidos de América. ${ }^{34}$

Una vez en puerto, para exportar mercancías novohispanas de alto valor, los nexos clientelares y burocráticos se pusieron en marcha. Para el 28 de mayo de 1799, a través del capitán de navío de puerto y maestranza de Veracruz Bernardo de Orta, el virrey de Nueva España, Miguel José de Azanza, autorizó la salida, desde San Juan de Ulúa, al Nancy, con registro de grana, azúcar y palo de tinte con destino a Santander, a consignación de Martín Olasagasti, vecino de Veracruz, y Juan Bautista Lobo, vecino de Jalapa. Mientras que para el 2 de junio de 1799, similar permiso se le dio al Franklin, cargado de palo de tinte, grana, azúcar y purga de Jalapa con destino a Santander, a cuenta y riesgo de la casa Porro y Murphy y representada por Juan Murphy, el dueño de los productos era Juan de Erice, vecino de La Habana. ${ }^{35}$

En ambos buques, sus capitanes, en representación de las casas mercantiles Tieman, Calman, Porro y Murphy, Olasagasti y Lobo solicitaron conjuntamente al gobernador e intendente de Veracruz, José García Dávila, se les otorgara un doble registro simulado "a fin de causionar estos intereses del riesgo de enemigos que les amenaza, si comprehendiesen que

${ }^{34}$ Juicio de Comiso (junio, 1799). (Marina, vol. 92, exp. 6, fs. 364-396v.; vol. 146, exp. único, fs. 261v.-262). Archivo General de la Nación, México.

${ }^{35}$ Juicio de Comiso (2 de junio de 1799). (Marina, vol. 92, exp. 6, f. 364; vol. 146, exp. único, fs. 10-10v., 261v.-262, 264v., 268-273v., 410v., 513). Archivo General de la Nación, México. 
la propiedad era española" ${ }^{36} \mathrm{Al}$ Franklin se le dio un registro falso escrito en inglés que hacía aparentar que la embarcación zarpó de Filadelfia con rumbo a Santander cargada de productos estadunidenses; el registro auténtico estaba redactado en castellano y contenía la descripción de mercancías de propiedad española con partida de Veracruz hacia Santander. $\mathrm{Al}$ igual que el anterior, el Nancy obtiene los dos tipos de registro, simulado de Baltimore a Santander y el verdadero de Veracruz hacia Santander. Estos registros de carga "fueron unos arbitrios para precaver de los riesgos de los ingleses la propiedad española", ${ }^{37}$ pues al ser avistado por un navío inglés mostrarían el registro de simulación, y en caso de ser detenido por un barco español bastaría con enseñar el verdadero.

Una vez habilitados y con ambos registros, el Nancy y el Franklin levaron anclas el 13 y 14 de junio, respectivamente, con escala en La Habana y destino final Santander; en algún punto del Golfo de México se reunieron para navegar en conjunto, pero aproximadamente a las once de la noche del día 18 de junio son interceptados por un barco, el cual desde su borda les pidió en idioma inglés un "santo y seña", iniciándose un largo proceso judicial para aclarar los "malentendidos" suscitados después del avistamiento, pues el buque interceptor era el barco corsario Bonaparte y el que les había hablado en inglés era el capitán Juan Chevallier. ${ }^{38}$

\section{CONFUSIÓN, LITIGIO Y SENTENCIA: EL NANCY, EL FRANKLIN y Juan Chevallier en CAMPeChe}

Ante la penumbra de la noche y habiendo escuchado la voz en inglés, la tripulación de los bergantines angloamericanos pensaron que se trataba de un buque británico, por lo cual el Franklin se rinde sin mostrar resistencia, cosa contraria con el Nancy que armado con sus seis cañones entabló un efímero combate, pues bastó un cañonazo de advertencia para que bajara su velamen. Viendo que el abordaje era inminente, los capitanes de ambos navíos "tiraron a la mar los registros fidedignos", cuál sería su sorpresa que la embarcación que los atacaba era una con "patente de corso española", con tripulación francesa, habanera y campechana, al mando de un francés. Los capitanes Andrés Morris y Felipe Aramberg al no tener más documentación que la escrita en inglés, explicaron el malentendido: que sus barcos

${ }^{36}$ Juicio de Comiso (29 de junio de 1799). (Marina, vol. 146, exp. único, fs. 217v., 266, 268, 271). Archivo General de la Nación, México.

${ }^{37}$ Juicio de Comiso (29 de junio de 1799). (Marina, vol. 146, exp. único, fs. 217v., 266, 268, 271). Archivo General de la Nación, México.

${ }^{38}$ Juicio de Comiso (19 de junio de 1799). (Marina, vol. 92, exp. 6, fs. 364-470; vol. 146, exp. único, f. 444v). Archivo General de la Nación, México. 
eran neutrales y que los registros que poseían eran simulados puesto que la carga era española, mas Juan Chevallier, hablándoles en castellano, les dijo: "el único registro e instrucción privada que son válidos son los que se presentan a bordo", ${ }^{39}$ no creyéndoles que los auténticos fueron arrojados al agua y que los productos iban a manos británicas.

Además, a bordo del Nancy se encontró una patente de corso estadunidense contra la república francesa. Este documento era dado por el Congreso estadunidense ante la denominada cuasi-guerra (1798-1800), conflicto no declarado formalmente entre el poder legislativo de Estados Unidos de América y la Francia revolucionaria, presentado casi por completo por sus fuerzas navales permanentes y buques armados en corso (Bonnel, 1961, pp. 48-114). Por los registros escritos en inglés y la patente contra Francia, Chevallier dio por buenas presas las embarcaciones y las dirigió hacia Campeche, ${ }^{40}$ no sin antes "clavar las escotillas y sellarlas de modo que no puedan abrirse sin romper el sello", como era señalado en el artículo XXVI de la ordenanza de corso española de $1796 .{ }^{41}$

Ya en puerto fueron asegurados los bajeles, iniciándose un juicio de comisos contenido en dos grupos destacados en el grafo: el primero, la parte acusadora, el corsario Juan Chevallier y sus armadores; el segundo, la defensa de los intereses de las compañías mercantiles estadunidenses y veracruzanas de ambos buques, las cuales fueron representadas por el abogado Juan Francisco Romay. Con base en los testimonios, tratados, leyes y vínculos personales de ambas camarillas, los ministros y autoridades de la Real Hacienda, representados por Manuel Palomeque y el gobierno virreinal, dictaminaron quién conservaría los bergantines y sus mercancías. ${ }^{42}$

Ante el Tribunal de Comiso, el grupo de Juan Chevallier estableció su principal defensa en el artículo XXXIV de la ordenanza de 1796 que establece: "Para determinar la legitimidad de presas no han de admitirse otros papeles que los encontrados a bordo. ${ }^{43}$ En palabras del capitán francés

se deben declarar por buenas las que navegan con papeles dobles, los arroje al agua o los lleve en blanco, en cuyas faltas han incurrido los citados bergantines, con la gravísima de tener el Nancy patente de corso y haber hecho fuego a la

${ }^{39}$ Juicio de Comiso (junio-septiembre de 1799). (Marina, vol. 92, exp. 6, fs. 364-470; vol. 146, exp. único, fs. 163-166). Archivo General de la Nación, México.

${ }^{40}$ Juicio de Comiso (octubre de 1799). (Marina, vol. 92, exp. 6, fs. 364-470). Archivo General de la Nación, México.

${ }^{41}$ Ordenanza de Corso (12 de octubre de 1796). (Bandos, vol. 11, exp. 23, fs. 54v.-55-55). Archivo General de la Nación, México.

${ }^{42}$ Juicio de Comiso (junio de 1799-21 de febrero de 1800). (Marina, vol. 146, exp. único, f. 418v). Archivo General de la Nación, México.

${ }^{43}$ Ordenanza de Corso (12 de octubre de 1796). (Bandos, vol. 11, exp. 23, f. 56). Archivo General de la Nación, México. 
bandera francesa [...] y es al almirantazgo francés único juez a quien se sujeta el que responde, que igualmente protesta contra los americanos y los comerciantes de Veracruz como contra aquellos de poco valor que permiten tan vil atropello. ${ }^{44}$

La actitud de insubordinación de Juan Chevallier no era un caso aislado, pues con la alianza militar franco-española se da un choque cultural entre los galos y los vasallos de su majestad católica, acentuándose "incompatibilidades de humor entre el francés exuberante y el español grave [...] los oficiales españoles se extrañaban de las faltas de educación manifiestas en el lenguaje y en las maneras de sus aliados: los juzgaban fanfarrones y vulgares, y su poco respeto hacia los poderes de la tierra y el cielo" (Carlan, 1951, pp. 26-27). Por lo que lógicamente y aún con el apoyo del Directorio de París, en Nueva España el discurso del corsario francés no logró convencer al virrey, ni a las autoridades del tribunal, todo lo contrario, se le tachó de hombre que odia a los capitanes americanos y que obtuvo su patente para asolar a las embarcaciones españolas y neutrales. ${ }^{45}$ Ante la inflexión y desacato de Chevallier, no es de extrañarse que se convirtiera en un personaje antagónico no sólo para los afectados de la requisa, sino de las propias autoridades españolas que podrían haberlo apoyado en la resolución de un fallo favorable.

En alusión a la patente de corso estadunidense contra la república francesa, Chevallier argumentó que "aunque neutrales [...] los Estados Unidos de América, enemigos de la Francia, con quien el monarca español se halla en estrecha alianza contra el enemigo común", ${ }^{46}$ por lo que era su deber requisar los buques, y el de las autoridades de Nueva España avalar sus acciones. Por lo visto el aprehensor extrajo la idea del Tratado de San Ildefonso de 1796, pero aquí salta a relucir que los estadunidenses no eran el enemigo común, pues este lo detentaron los ingleses, además de que desde el principio de las hostilidades se posicionaron como neutrales.

Respecto a las versiones de la defensa de las compañías mercantiles, el alegato de su representante, Juan Francisco Romay, se basó en que el acto de requisa fue injustificado, pues Juan Chevallier, al tener patente de corso española debió dar "respeto al pabellón de los neutrales y aliados de su Majestad Católica", como lo estipuló el Tratado Pinkey de 1795, donde en el artículo XIV existía la siguiente prohibición: "Ningún súbdito de Su Majestad Católica tomará encargo o patente para armar buques que

\footnotetext{
${ }^{44}$ Juicio de Comiso (29 de agosto de 1799). (Marina, vol. 146, exp. único, f. 171). Archivo General de la Nación, México.

${ }^{45}$ Juicio de Comiso (junio de 1799-21 de febrero de 1800). (Marina, vol. 146, exp. único, f. 171). Archivo General de la Nación, México.

${ }^{46}$ Juicio de Comiso (14 de julio de 1799). (Marina, vol. 146, exp. único, fs. 219v.-220). Archivo General de la Nación, México.
} 
obren como corsarios contra dichos Estados Unidos, o contra ciudadanos, pueblos o habitantes de alguno de ellos [...] Y si algún individuo de una u otra nación tomase semejantes encargos o patentes será considerado como pirata" (Castillo, 1843, p. 668).

En alusión a los registros de las mercancías transportadas, y gracias al testimonio del intendente de Veracruz, José García Dávila, Romay alegó que no debieron ser tomadas como buenas presas, ya que sí se pagaron los derechos correspondientes y las cargas eran de propiedad española. $\mathrm{El}$ arrojar los registros de carga verdaderos al agua y entregar los registros simulados, se debió a que era de noche y no pudieron distinguir la bandera de la embarcación que se les acercó, pero sobre todo que "el comandante corsario les habló en inglés tal como lo consta los autos por lo que arrojaron al agua los verdaderos". ${ }^{47}$

Referente a la patente de corso estadunidense en el Nancy, esta le fue otorgada legítimamente por el Congreso de Estado Unidos para "evitar se ultrajen y violenten por los corsarios franceses sus embarcaciones y propiedades americanas", pero sólo era válida a "todo barco armado francés que se encuentre entre la jurisdicción o límites de los Estados Unidos", ${ }^{48}$ por esta razón Chevallier no iba a ser atacado, ya que no se encontraba en la zona limítrofe de Estados Unidos de América, por lo que no existió razón de aprehensión por haber encontrado esa patente. ${ }^{49}$

Por último, en los testimonios brindados por Chevallier, no se aprecia cuál fue la embarcación corsaria que utilizó para realizar el patrullaje, la pesquisa y embargo de los bergantines, pues según las autoridades novohispanas, especialmente el virrey, se debía esclarecer tal incógnita, ya que de ello dependía la clase de leyes de protección y de responsabilidad a las que se hacía acreedor el galo corsario. Hay que recordar que el 23 de septiembre de 1798, en el Guárico, obtuvo del Directorio Ejecutivo de Santo Domingo una patente de corso francesa con duración de seis meses para la goleta Bonaparte de 40 toneladas y once cañones. Mientras que para el 4 de mayo de 1799 obtuvo del intendente de Yucatán una patente de corso española para un pequeño barco nombrado también Bonaparte o La Mosca de 25 toneladas y cuatro cañones, atracado en el puerto de Campeche. ${ }^{50}$

\footnotetext{
${ }^{47}$ Juicio de Comiso (junio de 1799). (Marina, vol. 146, exp. único, fs. 417-431, 442v., 444v). Archivo General de la Nación, México.

${ }^{48}$ Juicio de Comiso (4 de abril a 28 de noviembre de 1799). (Marina, vol. 146, exp. único, fs. 148v, 217, 302v., 442v). Archivo General de la Nación, México.

${ }^{49}$ Juicio de Comiso (4 de abril a 28 de noviembre de 1799). (Marina, vol. 146, exp. único, fs. 148v, 217, 302v., 442v). Archivo General de la Nación, México.

${ }^{50}$ Juicio de Comiso (23 de septiembre de 1798-4 de mayo de 1799). (Marina, vol. 92, exp. 6, fs. 442, 493; vol. 146, exp. único, fs. 23v., 127v., 136, 146, 156-156v., 160-162v., 260, 289, 351v., 358, 382, 391, 436v., 442v., 443, 446). Archivo General de la Nación, México.
} 
Sobre qué embarcación y patente fueron utilizadas por el francés durante la incautación en alta mar, se brinda la siguiente vicisitud. La parte afectada por el decomiso (las casas mercantiles Tieman, Calman, Porro y Murphy, Olasagasti y Lobo) manifestó a través de sus representantes que para el abordaje y la conducción de los bajeles a Campeche, no fue con la embarcación corsaria legítima (La Mosca Bonaparte) con patente española, sino con la goleta de 40 toneladas Bonaparte con patente francesa. Por ello, el abogado defensor sacó a relucir la aplicación del artículo XXVIII de la Ordenanza de Corso de 1796, en la que se establece que "no siendo lícito a mis vasallos en guerra embarcación alguna sin mi licencia, ni admitir a este fin patente o comisión de otro príncipe, o Estado, aunque sea aliado mío [sic]", Esta postura es ratificada por el intendente Arturo O’Nelli, quien informó que concedió armar una embarcación de 25 toneladas, pero desconocía que Chevallier había habilitado "en un primer momento la goleta Bonaparte [...] excediendo el número de armamento y hombres pasando a once cañones y 40 en lugar de la veintena de tripulación y los cuatro cañones concedidos" para un "barcucho" conocido como La Mosca, con el fin de hacer ver "maliciosamente" que la embarcación que salía era la más pequeña, la cual poseía la patente para hacer corso, pero la que realmente utilizó era un barco con mayor porte que no tenía permiso de las autoridades novohispanas.

Con ello, el gobierno español dejó en claro que si bien era legal y común poseer varias patentes de corso de múltiples regiones, estas sólo eran válidas si los permisos eran otorgados por autoridades españolas, y la aplicación del tratado de 1796, que autorizó la fusión de las fuerzas armadas entre Francia y España, sólo era válida en los ejércitos de tierra y mar permanentes, y no en la concesión de salvaguarda a particulares. Especulamos que esta renuencia de legitimar los actos de ambas embarcaciones llamadas Bonaparte, se debió no sólo por la difícil tarea de interpretar el mundo de las leyes casuísticas, sino que las palabras de Chevallier de que era el "almirantazgo francés único juez a quien se sujeta el que responde", ${ }^{51}$ pudo ser un detonante para ganarse la enemistad de las autoridades coloniales. En suma, para que fuesen legales las acciones corsarias de Chevallier, debieron hacerse bajo el permiso concedido a La Mosca y no a la goleta; además, si hubiera sido válida la patente francesa esta tenía una vigencia de seis meses desde el 23 de septiembre de 1798 hasta marzo de 1799, y puesto que el apresamiento se realizó en junio, la acción ya no era lícita. ${ }^{52}$

\footnotetext{
${ }^{51}$ Juicio de Comiso (19 de enero de 1800). (Marina, vol. 146, exp. único, fs. 171, 271, 289, 436v). Archivo General de la Nación, México.

${ }^{52}$ Juicio de Comiso (19 de enero de 1800). (Marina, vol. 146, exp. único, fs. 171, 271, 289, 436v). Archivo General de la Nación, México.
} 
Además de manifestar la irregularidad de utilizar un barco con registro francés para realizar revisiones en buques neutrales, los miembros de la red mercantil de los bajeles angloamericanos, también dieron interpretaciones falsas para recalcar las acciones piráticas de Juan Chevallier, como fueron sus afirmaciones de que el intendente de Yucatán no poseía la facultad de otorgar patentes de corso; esto fue desechado por el Tribunal de Comiso pues en reales cédulas concernientes a este sistema de seguridad se lee: "ordeno que los virreyes, gobernadores, intendentes o ministros encargados de este asunto en mis dominios de Indias después de recibidas a su satisfacción las fianzas que presentare el citado armador [...] le permitan pertrecharla y pularla con el número de gente que considere conveniente". ${ }^{53}$ Por lo que el permiso dado al galo en Campeche era legítimo para implementarlo en el barco de menor tamaño.

Al interpretar los hechos, tenemos que los incumplimientos de Juan Chevallier lo encasillan en la categoría creada por José Luis Azcárraga de Bustamante: un corso-pirata, ya que el barco con el que realizó las aprehensiones no poseía una patente legítima, con armamento y tripulación excesivos a los autorizados, razones por las que se cancelaba todo amparo que las autoridades españolas pudieran darle (Azcárraga, 1950, p. 25).

Aunado al proceso librado en Nueva España entre Chevallier y los afectados, gracias a la red de influencias del mercader Juan Murphy (Souto, 2001, pp. 277-332), logró que su voz de inconformidad resonara en el Congreso de Estados Unidos, el cual solicitó a la Corte de Madrid resolviera la ilegitimidad de los hechos, poniendo en tensión las relaciones diplomáticas y comerciales entre ambas instituciones. Por lo que los ministros de la Real Hacienda fueron presionados para que el veredicto fuera emitido lo antes posible. ${ }^{54}$ Así, en la ciudad de Mérida, el litigio duró de junio de 1799, fecha en que se abrió el litigio, al 21 de febrero de 1800, justo cuando los ministros del Tribunal de Comisos, representados por Manuel Palomeque, y ante las pruebas presentadas por ambas partes, sobre todo por las órdenes del rey Carlos IV, las del virrey de Nueva España, la presión del Congreso y de las casas comerciales de Estados Unidos de América y Veracruz, emitieron una sentencia: que las cargas decomisadas no son de contrabandistas, ni de ingleses, sino de propietarios españoles, siendo válidos tanto los registros verdaderos como los simulados, pues estos últimos los establecieron las autoridades del puerto con la finalidad de evitar riegos de enemigos. Se estableció que era ilícito el apresamiento

\footnotetext{
${ }^{53}$ Ordenanza de Corso (12 de octubre de 1796). (Bandos, vol. 11, exp. 24, fs. 64). Archivo General de la Nación, México.

${ }^{54}$ Juicio de Comiso (21 de febrero de 1800). (Marina, vol. 146, exp. único, fs. 401-479). Archivo General de la Nación, México.
} 
de los bergantines Nancy y Franklin, por lo que ni las tripulaciones ni sus capitanes, Felipe Aramberg y Andrés Morris, respectivamente, eran prisioneros de guerra; también, la restitución de los navíos y mercancía incautados a sus dueños o consignatarios, además de una indemnización tomada de la fianza del armador Juan Pinet, vecino de Campeche.

Bajo el cargo de piratería le fueron incautadas a Juan Chevalier ambas embarcaciones llamadas Bonaparte con todos sus pertrechos por haber utilizado dos barcos con patentes de corso diversas, y a la postre fueron sacadas a almoneda pública, y lo obtenido fue llevado a la Real Contaduría de Campeche.

Por último, Juan Chevalier, como oficial de marina de la república francesa, se le permitió salir de la provincia para ir a donde mejor le conviniera; se tiene noticias de que intentó apelar para llevar su caso a un juicio de segunda instancia, pero por mandato del virrey Miguel de la Grúa Talamanca y Branciforte no procedió la solicitud, ${ }^{55}$ con lo cual se pone fin al proceso judicial librado por el corsario galo.

En general, este juicio de comiso permite vislumbrar dos aspectos en el Caribe: uno, el comercio neutral de Estado Unidos de Norteamérica con Veracruz y España, y, por el otro, el corso utilizado por los aliados franceses que de manera auxiliar salvaguardaron las costas de contrabandistas o enemigos. Sin embargo, ambos factores representan las dos caras del mismo incentivo: el obtener una buena ganancia de las transacciones llevadas a cabo en el Seno Mexicano durante las guerras navales. Es así como el doble registro de simulación trajo más problemas que beneficios tanto a los dos bergantines angloamericanos que la usaron, como al corsario francés que no la consideró válida.

\section{COMENTARIOS FINALES}

En la búsqueda de mantener su dominio en los mares, Francia y España lanzaron conjuntamente sus fuerzas armadas de tierra y mar a una guerra que, en teoría, tuvo que dar respuesta a la expansión inglesa y castigar las agresiones cometidas por sus contrabandistas. Casi de inmediato fue evidente la primacía de Inglaterra; los continuos bloqueos y las constantes derrotas de las potencias aliadas caracterizaron este conflicto. Por su parte, España, para evitar los bloqueos, tuvo la "necesidad" de abrir sus puertos a barcos con pabellón neutral, donde los estadunidenses supieron destacar en tal concesión; referente a las derrotas, estas representaban

${ }^{55}$ Juicio de Comiso (21 de febrero de 1800). (Marina, vol. 146, exp. único, fs. 470-556v). Archivo General de la Nación, México. 
mermas en los buques de guerra y sin ellos la inseguridad en las rutas se acrecentó, teniendo que recurrir a la vieja tradición del corso; a cambio de la protección otorgada por su gobierno, el corsario se comprometía a respetar los barcos, personas y propiedades de la nación concesionaria y sus aliados, además de retribuir con una parte de los ingresos obtenidos por las capturas.

Durante las guerras navales el gobierno español buscó por cualquier medio mantener abiertos y seguros los intercambios ultramarinos, como parte de esta idea autorizó la apertura de dobles registros de carga: el verdadero escrito en castellano, que especifica el destino de la carga a un puerto español y sus dueños de la misma nacionalidad, y un registro falso en inglés, que señala a los productos como propiedad de agentes mercantiles y con puertos de desembarque en naciones neutrales. Con ello se buscó minimizar los riesgos de ser avistados por algún navío británico.

Pero los tratados comerciales y militares firmados por España no contemplaron la posibilidad de que sus aliados franceses, al obtener una patente de corso en Santo Domingo y otra en Nueva España, utilizaran la patente gala para incautar y trasladar barcos neutrales sospechosos de trasladar productos ingleses a puertos novohispanos. Tal como fue el caso de Juan Chevallier, un personaje que logró destacar por haber puesto en tensión las relaciones diplomáticas y comerciales de la monarquía española, los Estados Unidos de América y la Francia revolucionaria.

Desde un enfoque de análisis de la red egocéntrica del corsario galo, y sus consecuencias en los nexos en el comercio y las concesiones de patentes de corso en el Caribe, se ha logrado dilucidar el complejo contexto multifacético de las guerras navales, pues Chevallier al poseer dos buques con diferentes patentes, pretendió al velo de la noche decomisar los buques angloamericanos Nancy y Franklin, con registros simulados y fidedignos, atrayendo así la atención del intendente de Yucatán, el virrey y su soberano, quienes apoyaron los intereses de las casas comerciales estadunidenses y veracruzanas perjudicadas, pues de ellas dependía parte de los intercambios entre los territorios del imperio: por su parte, el corsario galo, producto de una naciente república, desdeñó los medios de descargo de pruebas realizados por las reales autoridades novohispanas.

Aunado a ello, durante el proceso judicial se vislumbró el informal conflicto llevado a cabo en el Caribe entre 1798 a 1800 por el Congreso de Estados Unidos de América y el Directorio de París, donde los buques mercantes de los primeros tuvieron la legitimidad de defenderse en sus aguas territoriales de los buques de la república. Es en esta parte donde se puede apreciar la delgada línea de los pactos llevados entre naciones y hasta donde un aliado de una deja de serlo para otra, mientras que el 
gobierno intermediario tuvo la difícil tarea de concertar los intereses de todos los involucrados.

En las guerras navales, el camino de la diplomacia y los intercambios económicos van de la mano, pero son las personalidades de los individuos las que dieron al acontecimiento analizado en estas páginas el sello casi caótico de lo que implicó utilizar patentes de corso de distintas naciones y dobles registros de simulación, quedando registrado en el juicio de comiso, el cual nos ha dado la oportunidad de dar un vistazo al crisol de interés gestados en el Caribe.

\section{LISTA DE REFERENCIAS}

AlCÁntARA, N. y CASAsola, S. P. (2002). La estrategia matrimonial de la red de poder de Guatemala colonial. En J. Gil y S. SchmidT (eds.), Análisis de redes. Aplicación en ciencias sociales (pp. 156-178). México: Universidad Nacional Autónoma de México/Instituto de Investigaciones en Matemáticas Aplicadas y en Sistemas.

AzCÁRraGa, J. L. DE (1950). El corso marítimo. Madrid: Consejo Superior de Investigaciones Científicas/Instituto Francisco de Victoria.

Bertrand, M. (1999a). Grandeur et misére de l'office. Les officiers de finances de Nouvelle Espagne XVIIe-XVIIIe siécles. París: Publications de la Sorbonne.

BERTRAND, M. (1999b). La élite colonial en la Nueva España del siglo XVIII: un planteamiento en términos de redes sociales. En B. SchrötTER y C. BÜschGES (eds.), Beneméritos, aristócratas y empresarios. Identidades y estructuras de las capas altas urbanas en América hispánica (pp. 35-51). Madrid: Vervuert Iberoamericana.

Bertrand, M. (abril-junio, 1999c). De la familia a la red de sociabilidad. Revista Mexicana de Sociología, 61(2), 107-135.

Bonnel, U. (1961). La France les états-unis et la guerre de course. París: Latines.

Brinkley, A. (2004). Historia de los Estados Unidos. Un país en formación. México: McGraw-Hill.

CACHIA, R. (diciembre, 2010). Las redes personales a la luz del análisis de redes sociales. Redes, Revista Hispana para el Análisis de Redes Sociales, 14, 7-30.

CARLAn J. M. (1951). Navios en secuestro. La escuadra española del Océano de Brest (17991802). Madrid: Instituto Histórico de Marina.

Castillo, A. (1843). Tratados y convenios y declaraciones de paz desde 1700 hasta el día de hoy (t. v). Madrid: Imprenta de Alegría y Charlain.

Castillo, P. (1992). La marina de guerra española en el primer tercio del siglo XIX (Organización, dotaciones, buques, arsenales y presupuestos). Madrid: Naval.

CLARK, L. (2006). Manual para el mapeo de redes como una herramienta de diagnóstico. Bolivia: Centro Internacional de Agricultura Tropical.

Cruz, O. (1997). El régimen jurídico del corso marítimo: el mundo indiano y el México del siglo $X I X$. México: Universidad Nacional Autónoma de México. 
Cruz, O. (2013). El corso marítimo. México: Universidad Nacional Autónoma de México.

Degenne, A. y Forsé, M. (2004). Introducing social networks. Londres: Sage.

Douglas, W., Schonegg, M., Brudner, L. A. y Nutini, H. G. (2002). Conectividad múltiple, fronteras e integración: parentesco y compadrazgo en Tlaxcala rural. En J. Gil y S. Schmidt (eds.), Análisis de redes. Aplicación en ciencias sociales (pp. 41-94). México: Universidad Nacional Autónoma de México.

FAUST, K. (2002). Las redes sociales en las ciencias sociales y del comportamiento. En J. Gil y S. Schmidt (eds.), Análisis de redes. Aplicación en ciencias sociales (pp. 1-14). México: Universidad Nacional Autónoma de México.

Fisher, J. R. (1990). Iberoamérica colonial. En M. LuCENA (coord.), Historia de Iberoamérica. Historia moderna (t. II, pp. 549-603). Madrid: Cátedra/Sociedad Estatal para la Ejecución de Programas del Quinto Centenario.

Fisher, J. R. (1993). El comercio entre España e Hispanoamérica (1797-1820) (Servicio de Estudios de Historia Económica, núm. 27). Madrid: Imprenta del Banco de España.

Freeman, L. (2002). Detectando grupos sociales en datos cuantitativos. En J. GiL y S. Schmidt (eds.), Análisis de redes. Aplicación en ciencias sociales (pp. 23-40). México: Universidad Nacional Autónoma de México.

Gil, J. y Schmidt, S. (eds.) (2002). Análisis de redes. Aplicación en ciencias sociales. México: Universidad Nacional Autónoma de México.

Grafenstein, J. vON (1997). Nueva España en el Circuncaribe. 1779-1800. Revolución, competencia imperial y vínculos intercoloniales. México: Universidad Nacional Autónoma de México.

Hausberger, B. e Ibarra, A. (eds.) (2003). Comercio y poder en América colonial: los consulados de comerciantes, siglo XVII-XIX. Madrid: Instituto Iberoamericano/Fundación Cultural Prusiano/Instituto de Investigaciones Dr. José Ma. Luis Mora.

Hernández, M. (1992). El mar en la historia de América. Madrid: MAPFre.

Holgado, D. (diciembre, 2010). Guía metodológica de análisis de redes sociales y redes personales. Redes. Revista Hispana para el Análisis de Redes Sociales, 14, 106-116.

IbARRA, A. y VALLE, G. DEL (coords.) (2007). Redes sociales e instituciones comerciales en el imperio español, siglos XVII a XIX. México: Instituto de Investigaciones Dr. José María Luis Mora/Universidad Nacional Autónoma de México.

Jiménez, G. (2000). El comercio clandestino. 1797-1811. En C. Yuste y M. Souto (coords.), El comercio exterior de México 1713-1850. Entre la quiebra del sistema imperial y el surgimiento de una nación (pp. 193-206). México: Instituto de Investigaciones Dr. José Ma. Luis Mora/Universidad Nacional Autónoma de México.

LÁszló, A. (2002). Linked. The new science of networks. París: Perseus.

Lucena, M. (coord.) (1990). Historia de Iberoamérica. Historia moderna (t. II). Madrid: Cátedra.

Lucena, M. (1992). Piratas. Bucaneros, filibusteros, y corsarios en América. Perros, mendigos y otros malditos de mar. Madrid: MAPFRE. 
MARICHAL, C. (2000). El comercio neutral y los consorcios extranjeros en Veracruz. 1805-1808. En C. Yuste y M. Souto (coords.), El comercio exterior de México 17131850. Entre la quiebra del sistema imperial y el surgimiento de una nación (pp. 163-192). México: Instituto de Investigaciones Dr. José Ma. Luis Mora/Universidad Nacional Autónoma de México.

MAzzeO, C. (2003). El Consulado de Lima y la política comercial española frente a las coyunturas de cambio de fines del periodo colonial (1806-1821). En B. HAUSBERGER y A. IbARRA (eds.), Comercio y poder en América colonial: los consulados de comerciantes, siglo XVII-XIX (pp. 199-223). Madrid: Instituto Iberoamericano/Fundación Cultural Prusiano/Instituto de Investigaciones Dr. José Ma. Luis Mora.

Merelo, J. J. (2004). Redes sociales: una introducción. España: Universidad de Granada.

Molina, J. L. (junio, 2004). La ciencia de las redes. Apuntes de Ciencia y Tecnología, 11, 36-41.

Molina, J. L. (2009). Taller introductorio al análisis de redes sociales. Prácticas con Netminer y Pajek. Barcelona: Universidad Autónoma de Barcelona.

Moutoukias, Z. (1989). Burocracia, contrabando y la autotransformación de la élite. Buenos Aires en el siglo XVII. Anuario del IEHS, 3, 213-248.

Moutoukias, Z. (1997). Negocios y redes sociales: modelo interpretativo a partir del caso riopaltense (siglo XVIII). Caravelle, 67, 37-55.

Moutoukias, Z. (1998). Redes sociales, comportamiento empresario y movilidad social en una economía de no mercado (el Río de la Plata en la segunda mitad del siglo XVIII). En B. Zeberio, M. BJERG y H. Otero (comps.), Reproducción social y sistemas de herencia en una perspectiva comparada. Europa y los países nuevos, siglos XVIII al XIX (pp. 63-81). Buenos Aires: Tandil, IEHS.

Ortiz de la Tabla, J. (1978). Comercio exterior de Veracruz 1778-1821, crisis de dependencia. Sevilla: Escuela de Estudios Hispanoamericanos.

Perusset, M. (enero-junio, 2007). Ilicit behavior: Smuggling and society in seventeenth-century Buenos Aires. Crítica, 293(33), 158-185.

Rodríguez, M. DEL R. (coord.) (2000). El Caribe. Intereses geopolíticos y dominación colonial. México: Universidad Michoacana de San Nicolás de Hidalgo.

Rodríguez, J. C. (2007). Los corsarios hispanos y franceses en el Seno Mexicano. 1796-1808. ¿Combatientes o cómplices del comercio ilícito? (Tesis de maestría inédita). Instituto de Investigaciones Dr. José Ma. Luis Mora, México.

Rosal, M. Á. (1989). Transportes terrestres y circulación de mercancías en el espacio rioplatense. 1781-1811. Anuario del Instituto de Estudios Histórico, 3, 213-248.

SÁNCHEZ, E. (enero-marzo, 2007). Las incertidumbres del cambio: redes sociales y mercantiles de los hacendados azucareros del centro de México (1800-1834). Historia Mexicana, 56(3), 919-967.

ScOTT, J. (1991). Social network analysis. Londres: Sage.

Souto, M. (2001). Mar abierto. La política y el comercio del Consulado de Veracruz en el ocaso del sistema imperial. México: El Colegio de México/Instituto de Investigaciones Dr. José Ma. Luis Mora. 
Stapells, V. (1992). Los corsarios de Santo Domingo, 1718-1779: Un estudio socioecónomico (Colección Espai/Temps núm. 12, Quaderns del Departament de Geografia i Historia de l'Estudi General de Lleida). España: Universitat de Lleida.

SuÁREZ, C. E. (10 de octubre, 2004). Redes sociales e instituciones comerciales en México, siglos XVII-XIX. Las redes familiares y sociales de un transportista novohispano: Pedro de Vértiz. 1760-1802 (pp. 1-30). II Congreso Nacional de Historia Económica. Centro de Investigaciones y Estudios Superiores en Antropología Social, México.

TANDRÓN, H. (1976). El comercio de Nueva España y la controversia sobre la libertad de comercio. 1796-1821. México: Instituto Mexicano del Comercio Exterior.

Velázquez, O., Aguilar, A. y Gallegos, N. (2005). Manual introductorio al análisis de redes sociales. Medidas de centralidad y ejemplos prácticos con UCINET 6.85 y NETDRAW 1.48. México: Universidad Autónoma del Estado de México/Centro de Capacitación y Evaluación para el Desarrollo Rural/Universidad Autónoma Chapingo.

Villalobos, S. (1965). Comercio y contrabando en el Río de la Plata y Chile. 1700-1811. Buenos Aires: Universidad de Buenos Aires.

WatTs, D. J. (1999). Small Worlds. The dynamics of networks between order and randomness. Princeton: Princeton University Press.

Zapatero, J. M. (1964). La guerra del Caribe en el siglo XVIII. Puerto Rico: Instituto de Cultura de Puerto Rico. 